\title{
Nematotoxic and phytotoxic activity of Satureja montana and Ruta graveolens essential oils on Pinus pinaster shoot cultures and $P$. pinaster with Bursaphelenchus xylophilus in vitro co-cultures
}

\author{
Jorge M.S. Faria ${ }^{a}$, Inês Sena ${ }^{a}$, Cristina Moiteiro ${ }^{b}$, Richard N. Bennett ${ }^{c}$, Manuel Mota ${ }^{\mathrm{d}}$, \\ A.Cristina Figueiredo ${ }^{\mathrm{a}, *}$ \\ a Centro de Estudos do Ambiente e do Mar Lisboa, Faculdade de Ciências, Universidade de Lisboa, CBV, 1749-016 Lisboa, Portugal \\ b Centro de Química e Bioquímica, Faculdade de Ciências, Universidade de Lisboa, Campo Grande, 1749-016, Lisboa, Portugal \\ c Universidade de Trás-os-Montes e Alto Douro, Quinta dos Prados-Apartado 1013, 5000-911 Vila Real, Portugal \\ d NemaLab, ICAAM-Instituto de Ciências Agrárias e Ambientais Mediterrânicas, Universidade de Évora, Núcleo da Mitra, Ap. 94, 7002-554 Évora, Portugal
}

\section{A R T I C L E I N F O}

\section{Article history:}

Received 31 March 2015

Received in revised form 21 July 2015

Accepted 20 August 2015

\section{Keywords:}

Carvacrol

Monoxenic culture

Pine wilt disease

Pinewood nematode

Volatiles

2-Undecanone

\begin{abstract}
A B S T R A C T
Satureja montana (winter savory) and Ruta graveolens (rue) nematotoxic essential oils (EOs) $(0.5 \mu \mathrm{lEO} / \mathrm{ml}$ culture medium) were assessed for the first time in Pinus pinaster in vitro shoot cultures (Ppi) and $P$. pinaster shoots with Bursaphelenchus xylophilus co-cultures (PpiBx). The EOs nematotoxic effect was evaluated on B. xylophilus population density in PpiBx co-cultures and the phytotoxic activity to the host was assessed by evaluating relative water content and volatile profiles both on Ppi cultures and on PpiBx co-cultures. Carvacrol-rich S. montana EO showed phytotoxicity, by inducing shoot chlorosis and drooping, whereas no major morphological changes were detected on R. graveolens EO-added Ppi and PpiBx in vitro cultures. Both EOs maintained the nematotoxicity during all experimental phases. $R$. graveolens EO proved to be an effective PWN antagonist to be further evaluated for pine wilt disease control, given its less phytotoxicity while maintaining nematoxicity.
\end{abstract}

(c) 2015 Elsevier B.V. All rights reserved.

\section{Introduction}

The pine wilt disease (PWD) pathogenic agent, pinewood nematode (PWN), Bursaphelenchus xylophilus (Steiner and Buhrer) Nickle was classified as an A2 type quarantine pest by the European and Mediterranean Plant Protection Organization (EPPO, 2012). It is commonly controlled by controlling the insect vector or the nematode through the use of insecticides or nematicides, yet these are associated with environmental pollution and undesirable influences on human health or non-target organisms (Mota and Vieira, 2008). As potential phytochemical alternatives, essential oils (EOs) show low toxicity to mammals, are biodegradable, and do not accumulate in the environment (Figueiredo et al., 2008). EOs PWN nematoxicity has been extensively researched, mainly by means of direct contact bioassays (Barbosa et al., 2010, 2012; Andrés et al., 2012). From screening 59 plant species EOs, Faria et al.

\footnotetext{
* Correspondence author.

E-mail addresses: jmfaria@fc.ul.pt (J.M.S. Faria), ines.carvalho.sena@gmail.com (I. Sena), cmmoiteiro@fc.ul.pt (C. Moiteiro), rnbennett@utad.pt (R.N. Bennett), mmota@uevora.pt (M. Mota), acsf@fc.ul.pt (A.Cristina Figueiredo).
}

(2013) identified highly PWN nematotoxic Satureja montana L. (winter savory) and Ruta graveolens L. (rue) EOs, with $\mathrm{LC}_{100 / 24 \mathrm{~h}}$ $<0.4 \mu \mathrm{l} / \mathrm{ml}$. EO fractions were also evaluated revealing, in general, oxygen-containing molecules fractions with higher activities than hydrocarbon molecules fractions, the later fractions contributing, on a plant specific manner, to the overall EO nematoxicity. Nevertheless, direct contact bioassays do not take into account toxicity for the host or the plant's capability to biotransform the nematotoxic active substances. On the other hand, greenhouse and field assays are very laborious and, many times, environmentdependent. In vitro co-cultures constitute a laboratory model, allowing analysis of metabolomic interplay between plant and nematode at various levels, namely to follow directly the host and nematode response to phytonematotoxics application, at various stages of infection (Faria et al., 2014, 2015).

The present work is the first report on the use of plant with nematode co-cultures as models for screening effective nematotoxic EOs. Using previously established (Faria et al., 2015), Pinus pinaster in vitro shoot cultures and $P$. pinaster shoots with $\mathrm{PWN}$ cocultures, the present study aims at evaluating the nematotoxic and phytotoxic activities of $S$. montana and R. graveolens EOs by assess- 
ing the nematode density in the co-cultures, the relative water content and volatile profiles of both in vitro cultures types.

\section{Material and methods}

\subsection{Pine shoot cultures and pine shoots with nematode co-cultures}

$P$. pinaster in vitro shoot cultures (Ppi) and $P$. pinaster shoots with PWN co-cultures (PpiBx) were established as detailed in Faria et al. (2015), and maintained in Combiness ${ }^{\circledR}$ (Belgium) microboxes $[8 \mathrm{~cm}$ base diameter per $6 \mathrm{~cm}$ height, with the green filter $(\mathrm{XXL}+)$ on the lid, to facilitate air exchange], containing $20 \mathrm{ml} \mathrm{SH}$ solid medium (Schenk and Hildebrandt, 1972) with $30 \mathrm{~g} / \mathrm{l}$ sucrose, at $24 \pm 1{ }^{\circ} \mathrm{C}$ under a $16 \mathrm{~h}$ light photoperiod [cool fluorescent lamps ( $\left.32 \mu \mathrm{E} / \mathrm{m}^{2} / \mathrm{s}\right)$ ]. Routine subculture was performed every four weeks.

\subsection{R. graveolens and S. montana essential oils nematotoxic and phytotoxic activity}

The effect of $R$. graveolens ( $\mathrm{Rg}$ ) and S. montana (Sm) EOs, at $0.5 \mu \mathrm{l} / \mathrm{ml}$, was assessed both on (a) Ppi cultures and (b) PpiBx cocultures, Fig. 1. The EOs nematotoxic effect was evaluated on $B$. xylophilus population density in PpiBx co-cultures, and the phytotoxic activity to the host was assessed both on Ppi cultures and on PpiBx co-cultures. For Ppi cultures, after 7 days of growth in regular SH solid medium (Phase 1), the cultures were transferred, for 7 days, to SH solid medium without, or with EO (Phase 2), and then again transferred to regular SH solid medium, for 7 days (Phase 3, recovery time), Fig. 1. PpiBx co-cultures were established by adding a $100 \mu$ l suspension ( $250 \pm 50$ PWNs) into a small hole made in the culture medium into which the cut end of $P$. pinaster shoot (Ppi) was inserted, and maintained for 7 days for nematode infection (Phase 1). PpiBx co-cultures Phase 2 and 3 were run as detailed for Ppi cultures. Sampling was performed at the beginning (time 0 ), at days 1,2 and 7 of Phase 2 and at the end of recovery time (day 7 of Phase 3). In both cases, control cultures (without addition of EO) were maintained simultaneously, under the same growth conditions. To prepare $\mathrm{SH}$ solid medium with EO, a solution of EO in methanol $(1: 1, \mathrm{v} / \mathrm{v})$ was added, in asepsis with agitation, to previously autoclaved medium $\left(121^{\circ} \mathrm{C}\right.$ for $\left.15 \mathrm{~min}\right)$ after reaching room temperature, in such a way as to give $0.5 \mu \mathrm{l} \mathrm{EO} / \mathrm{ml}$ culture medium. EO evaporation and decomposition control experiments were performed by adding the same amount of EO to microboxes containing only regular culture medium, and keeping them in the same conditions as the experimental ones. Two independent experiments were separately run and 4 replicates per experimental time-point were used in each experiment. The data shown were calculated as mean values of all experiments. All statistical analyses were performed using Microsoft Excel 2013. The effect of adding S. montana and $R$. graveolens EOs to Ppi cultures and PpiBx co-cultures was followed by measuring relative water content (RWC), nematode density in the culture medium and in vitro volatiles production as in Faria et al. (2015).

\subsection{R. graveolens and S. montana essential oils}

Satureja montana and $R$. graveolens EOs were isolated from the dried aerial parts sold in local herbal shops and the chemical profiling was performed as detailed in Faria et al. (2013). Volatiles were analyzed by gas chromatography (GC), for component quantification, and gas chromatography coupled to mass spectrometry (GC-MS) for component identification.

Gas chromatographic analyses were performed using a Perkin Elmer Autosystem XL gas chromatograph (PerkinElmer, Shelton,
CT, USA) equipped with two flame ionization detectors (FIDs), a data handling system, and a vaporizing injector port into which two columns of different polarities were installed: a DB-1 fusedsilica column $(30 \mathrm{~m} \times 0.25 \mathrm{~mm}$ i.d., film thickness $0.25 \mu \mathrm{m}$; J \& W Scientific Inc., Rancho Cordova, CA, USA) and a DB-17HT fusedsilica column ( $30 \mathrm{~m} \times 0.25 \mathrm{~mm}$ i.d., film thickness $0.15 \mu \mathrm{m}$; J \& W Scientific Inc., Rancho Cordova, CA, USA). Oven temperature was programmed to increase from 45 to $175^{\circ} \mathrm{C}$, at $3^{\circ} \mathrm{C} / \mathrm{min}$ increments, then up to $300^{\circ} \mathrm{C}$ at $15^{\circ} \mathrm{C} / \mathrm{min}$ increments, and finally held isothermal for $10 \mathrm{~min}$. Gas chromatographic settings were as follows: injector and detectors temperatures, $280^{\circ} \mathrm{C}$ and $300^{\circ} \mathrm{C}$, respectively; carrier gas, hydrogen, adjusted to a linear velocity of $30 \mathrm{~cm} / \mathrm{s}$. The samples were injected using a split sampling technique, ratio $1: 50$. The volume of injection was $0.1 \mu \mathrm{l}$ of a pentane-oil solution $(1: 1)$. The percentage composition of the oils was computed by the normalization method from the GC peak areas, calculated as a mean value of two injections from each volatile oil, without response factors.

The GC-MS unit consisted of a PerkinElmer Autosystem XL gas chromatograph, equipped with DB-1 fused-silica column ( $30 \mathrm{~m} \times 0.25 \mathrm{~mm}$ i.d., film thickness $0.25 \mu \mathrm{m}$; J \& W Scientific, Inc., Rancho Cordova, CA, USA) interfaced with PerkinElmer Turbomass mass spectrometer (software version 4.1, Perkin Elmer). GC-MS settings were as follows: injector and oven temperatures were as above; transfer line temperature, $280^{\circ} \mathrm{C}$; ion source temperature, $220^{\circ} \mathrm{C}$; carrier gas, helium, adjusted to a linear velocity of $30 \mathrm{~cm} / \mathrm{s}$; split ratio, 1:40; ionization energy, $70 \mathrm{eV}$; scan range, $40-300 \mathrm{u}$; scan time, $1 \mathrm{~s}$. The identity of the components was assigned by comparison of their retention indices relative to $\mathrm{C}_{8}-\mathrm{C}_{25} n$ alkane indices, and GC-MS spectra from a laboratory made library based upon the analyses of reference oils, laboratory-synthesized components, and commercial available standards.

\subsubsection{Isolation and identification of 8-phenyl-2-octanone}

Given the presence of an unidentified compound $>7 \%$, in R. graveolens EO (compound UI E, in Faria et al., 2013 supplementary table), this was further fractionated for compound isolation and identification. Hydrocarbon molecules (HM) and oxygen-containing molecules (OCM) were fractionated according to Faria et al. (2013). EOs were fractionated on a silica gel column by successive elution with distilled $n$-pentane and diethyl ether. The fractions were analyzed by gas chromatography coupled to mass spectrometry (GC-MS) and purified according to Figueiredo et al. (1992). OCM fractions (approximately $0.2 \mathrm{ml}$ each in a total of $1.4 \mathrm{ml}$ ) were separated twice on silica gel plates (60 $\mathrm{F}_{254}$, Merck, $20 \times 20 \mathrm{~cm}, 1 \mathrm{~mm}$ layer thickness) using $n$-hexane : ethyl acetate (95:5) as eluent. The fraction obtained (7.4 mg) was characterized and identified by NMR spectroscopy and GC-MS spectrometry. 1D NMR $\left({ }^{1} \mathrm{H},{ }^{13} \mathrm{C}\right.$ and APT) and 2D NMR (HSQC, HMBC and COSY) spectra were recorded on Bruker spectrometer CXP400 operating at $400.13 \mathrm{MHz}\left({ }^{1} \mathrm{H}\right)$ and $100.61 \mathrm{MHz}\left({ }^{13} \mathrm{C}\right)$. All chemical shifts are given at ppm and using $\mathrm{CD}_{2} \mathrm{Cl}_{2}$ signals as reference $(\delta=5.30 \mathrm{ppm})$. Identification was as follows: ${ }^{1} \mathrm{H}$ RMN $(400 \mathrm{MHz}$, $\left.\mathrm{CD}_{2} \mathrm{Cl}_{2}\right) \delta$ 7.29-7.21 (m, 2H, H-11, H-11'), 7.20-7.12 (m, 3H, H-10, $\mathrm{H}-10^{\prime}, \mathrm{H}-12$ ), 2.59 (t, $\left.2 \mathrm{H}, J=7.6 \mathrm{~Hz}, \mathrm{CH}_{2}-8\right), 2.39$ (t, $2 \mathrm{H}, J=7.6 \mathrm{~Hz}$, $\left.\mathrm{CH}_{2}-3\right), 2.08\left(\mathrm{~s}, 3 \mathrm{H}, \mathrm{CH}_{3}-1\right), 1.65-1.48\left(\mathrm{~m}, 4 \mathrm{H}, \mathrm{CH}_{2}-7\right.$ and $\left.\mathrm{CH}_{2}-4\right)$, 1.36-1.27 (m, $4 \mathrm{H}, \mathrm{CH}_{2}-5$ and $\left.\mathrm{CH}_{2}-6\right) ;{ }^{13} \mathrm{C}$ RMN (101 MHz, $\mathrm{CD}_{2} \mathrm{Cl}_{2}$ ) $\delta 209.5$ (C-2), 143.5 (C-9), 128.9 (C-10, C-10'), 126.1 (C-12), 128.7 (C-11, C-11'), 44.1 (C-3), 36.4 (C-8), 30.1 (C-1), 32.0, 24.3 (C-7 and C-4), 29.6, 29.5 (C-5 and C-6); MS (EI, $70 \mathrm{eV}) \mathrm{m} / \mathrm{z}\left(\mathrm{C}_{14} \mathrm{H}_{20} \mathrm{O}\right): 204$ $(\mathrm{M})^{+}(0), 186\left(\mathrm{M}-\mathrm{H}_{2} \mathrm{O}\right)^{+}(30), 130(10), 105\left(\mathrm{C}_{6} \mathrm{H}_{5} \mathrm{CO}\right)^{+}(20), 104$ $\left(\mathrm{C}_{7} \mathrm{H}_{7}\right)^{+}(98), 91\left(\mathrm{C}_{7} \mathrm{H}_{7}\right)^{+}(100), 82(14), 71(30), 65(15), 58(10), 43$ (60). 


\section{a) Pinus pinaster in vitro shoots culture (Ppi)}

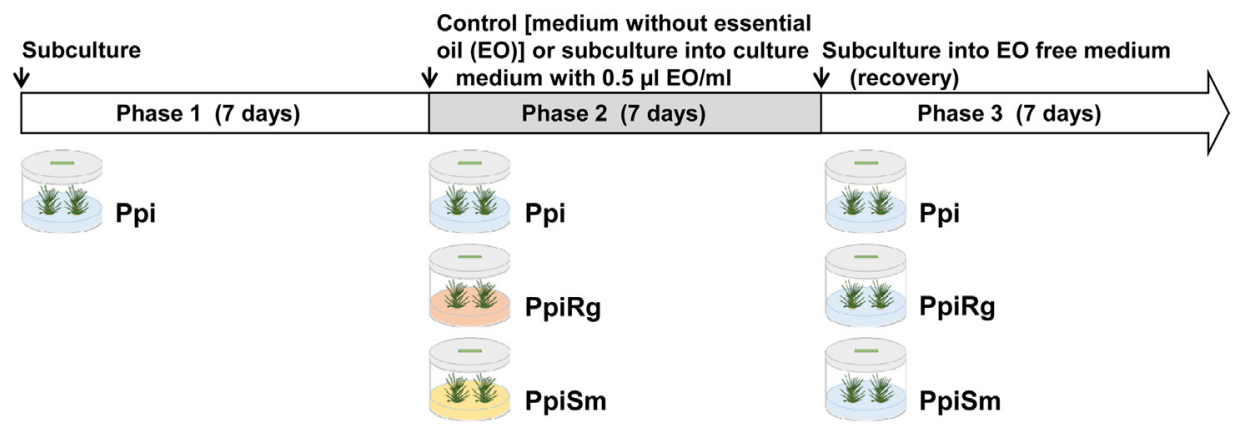

b) Pinus pinaster shoots with PWN co-culture (PpiBx)

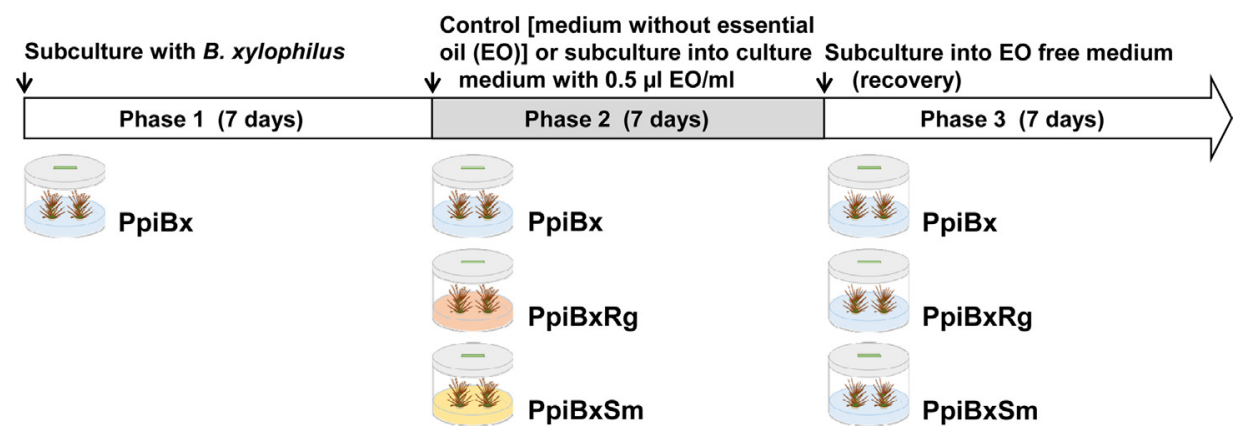

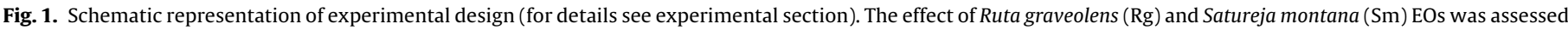
both on (a) Pinus pinaster in vitro shoot cultures (Ppi) and (b) P. pinaster shoots with PWN co-cultures (PpiBx).

\section{Results and discussion}

\subsection{Phytotoxicity to P. pinaster shoot cultures}

P. pinaster shoots (Ppi) showed both the typical in vitro pine macroscopic aspect, green upright shoots with straight pine needles (Fig. 2a), and similar volatiles composition (Table 1), to that previously reported (Faria et al., 2015). The isolated constitutive volatiles showed no substantial differences in composition throughout experimental time. Table 1 reports the full chemical characterization of the volatiles isolated, in a total of $46 \mathrm{com}-$ pounds. Volatiles were dominated by $\beta$-pinene (35-47\%), $\alpha$-pinene (18-29\%), an unidentified compound (UI B Ppi) (3-10\%), germacrene $\mathrm{D}(3-9 \%)$ and $\beta$-caryophyllene (1-3\%).

The phytotoxic effect of adding S. montana EO to the culture medium was noticeable by day 2 and the chlorotic and drooping shoots observable at day 7 of Phase 2 (Fig. 2b) were not able to recover after 7 days in EO-free culture medium (Phase 3). Despite this aspect, Ppi shoots RWC range was $80-85 \%$ (Fig. 3), probably due to the in vitro culture generally fully saturated water content environment.

In addition to $S$. montana EO compounds, and to Ppi shoots constitutive volatiles, also new volatiles were detected in Ppi shoots S. montana EO added cultures. Of the main S. montana EO components (carvacrol 64\% and $\gamma$-terpinene 18\%) (Faria et al., 2013), only carvacrol was detected in high relative amounts, increasing to the end of the experimental time (67-80\%) (Fig. 4a). $\gamma$-Terpinene maximum detected was $0.1 \%$, at 0,1 and 2 days of Phase 2 , and remained at trace amounts thereafter. Part of this decrease can be due to volatilization, as this was also detected in controls of EO evaporation and decomposition (carvacrol 95-97\% and $\gamma$-terpinene $0.4-0.5 \%$ ). Nevertheless, since in vitro cultures are known to have biotransformation capacity (Giri et al., 2001; Faria et al., 2009; Nunes et al., 2009), the conversion of $\gamma$-terpinene into a non- volatile glycosylated form, can also partly explain the difference between $\gamma$-terpinene percentage in S. montana EO and in S. montana EO added cultures (PpiSm). Despite the transference of the shoots to EO-free medium, at the end of phase 3 (recovery time), carvacrol was still detected in high relative amount (19\%). As a probable phytotoxic effect, and opposite of constitutive volatiles from control Ppi shoots, the PpiSm monoterpenes percentage was lower than that of sesquiterpenes, palmitic acid, or the unidentified compound B. Moreover, two new volatiles were detected in PpiSm shoots, 2 -undecane, detected in trace amounts, and pentadecanal, $<2 \%$ throughout the experimental time.

S. montana EOs are commonly dominated by carvacrol, $\gamma$ terpinene and $p$-cymene which have been associated to its phytotoxic activity. In assays analyzing the activity of EOs in weeds and crops seeds germination, S. montana EO showed to be damaging to both, making it a poor choice for an herbicidal pesticide. Angelini et al. (2003) tested the EO at $0.5 \mathrm{mg} / \mathrm{ml}$, and also its main compound carvacrol (57\%), and found it to be highly inhibitory against in vitro seed germination. Grosso et al. (2010) also obtained high phytotoxic activity applying carvacrol-rich S. montana EO (52\%) to 4 crops and 3 weed seeds and seedlings in vitro. Both germination and seedling root/shoot growth were affected negatively making this herbicidal EO only appropriate for uncultivated fields. Albuquerque et al. (2012) tested both carvacrol and its isomer thymol, at $0.4 \mu \mathrm{l}$ EO per ml culture medium, on in vitro shoot cultures of Heliconia psittacorum $\times$ Heliconia spathocircinata var. Golden Torch. Their highly damaging effect was due to general destruction of the cell membranes and coagulation of the cytoplasm, detected through transmission electron microscopy. S. montana EOs appear not to be a sound choice for application as nematode biopesticides given their very negative effect on plant growth and development.

No macroscopic negative effect was detected after transferring Ppi shoots into R. graveolens EO-added culture medium (PpiRg) at phase 2 (Fig. 2c). As for S. montana EO, also in this case, in addition 

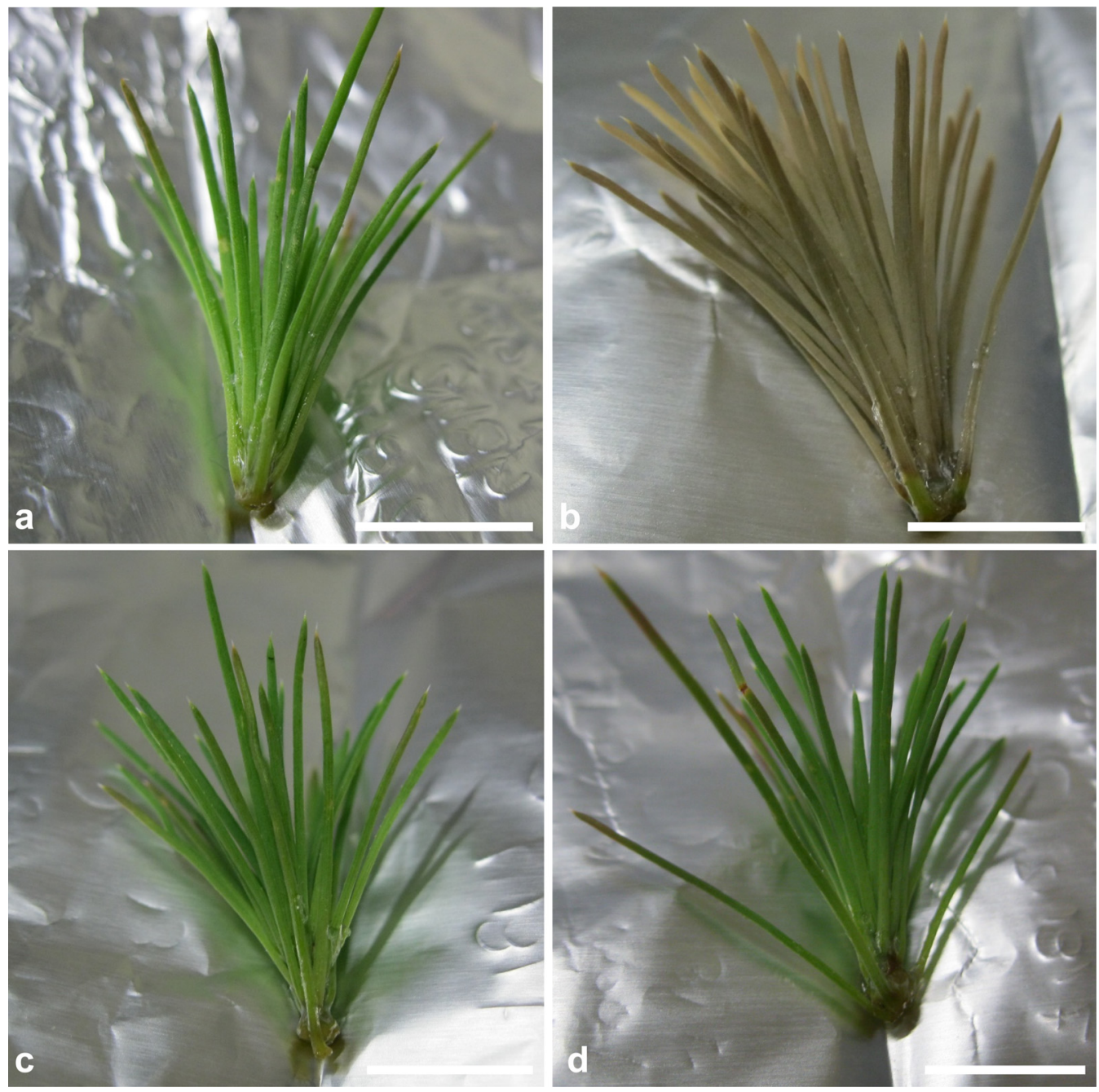

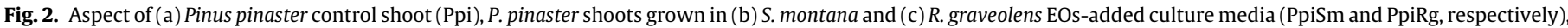

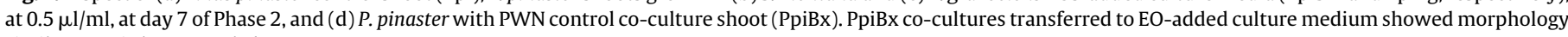
similar to Ppi shoots. Scale bar $1 \mathrm{~cm}$.

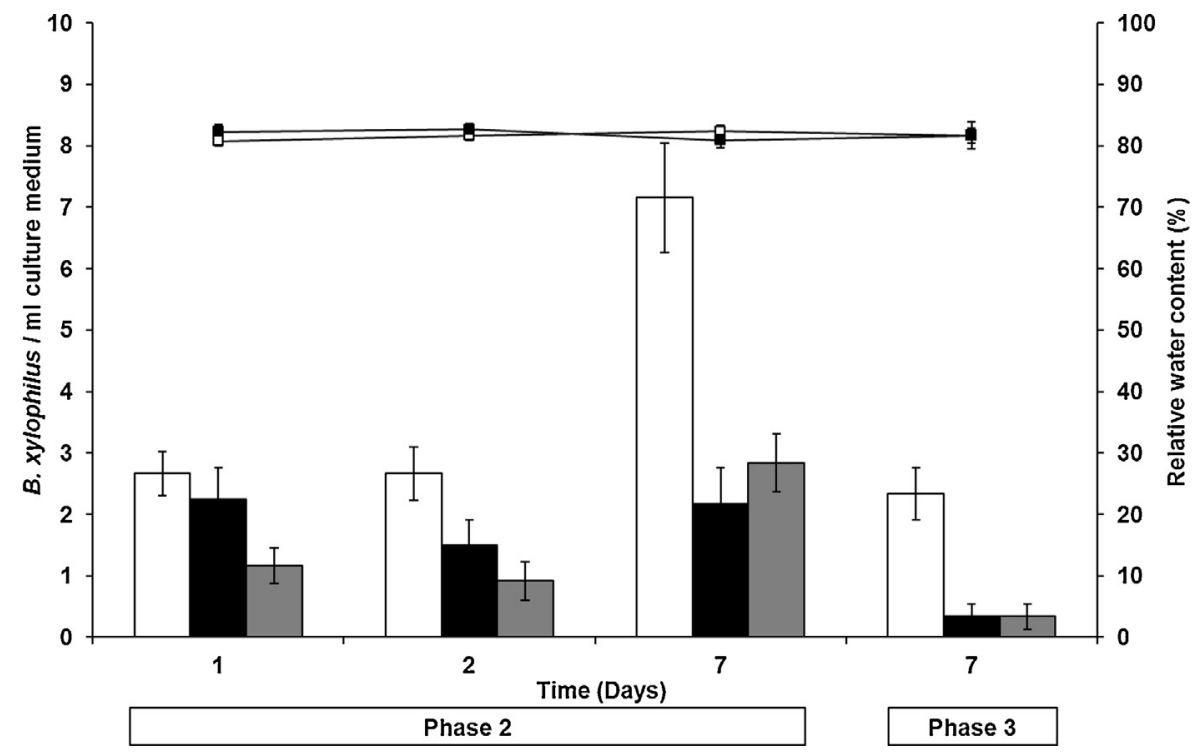

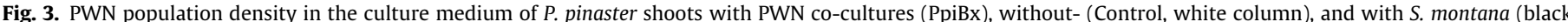

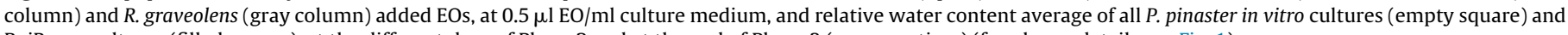
PpiBx co-cultures (filled square), at the different days of Phase 2 and at the end of Phase 3 (recovery time) (for phases details see Fig. 1 ). 
Table 1

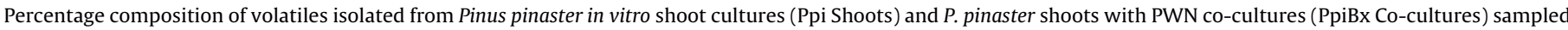
at time 0 , and days 1, 2 and 7 of Phase 2 and at the end of recovery time (R, day 7 of Phase 3). For experimental design see Fig. 1.

\begin{tabular}{|c|c|c|c|c|c|c|c|c|c|c|c|}
\hline \multirow[t]{2}{*}{ Components } & \multirow[t]{2}{*}{ RI } & \multicolumn{5}{|c|}{ Ppi Shoots } & \multicolumn{5}{|c|}{ PpiBx Co-cultures } \\
\hline & & 0 & 1 & 2 & 7 & $\mathrm{R}$ & 0 & 1 & 2 & 7 & $\mathrm{R}$ \\
\hline trans-2-Hexenal & 866 & 0.1 & 0.1 & $\mathrm{t}$ & 0.1 & $\mathrm{t}$ & 0.1 & 0.1 & $\mathrm{t}$ & $\mathrm{t}$ & $\mathrm{t}$ \\
\hline$\alpha$-Thujene & 924 & 0.1 & 0.2 & 0.2 & 0.3 & 0.2 & 0.1 & 0.2 & 0.1 & 0.4 & $\mathrm{t}$ \\
\hline$\alpha$-Pinene & 930 & 24.4 & 26.6 & 25.9 & 28.7 & 24.6 & 25.4 & 28.2 & 17.7 & 29.4 & 20.5 \\
\hline Camphene & 938 & 0.5 & 0.6 & 0.6 & 0.7 & 0.5 & 0.6 & 0.8 & 0.4 & 0.7 & 0.2 \\
\hline Sabinene & 958 & $\mathrm{t}$ & $\mathrm{t}$ & $\mathrm{t}$ & $\mathrm{t}$ & $\mathrm{t}$ & $\mathrm{t}$ & $\mathrm{t}$ & $\mathrm{t}$ & $\mathrm{t}$ & $\mathrm{t}$ \\
\hline$\beta$-Pinene & 963 & 42.4 & 44.1 & 41.3 & 45.7 & 40.2 & 39.7 & 45.5 & 35.3 & 47.2 & 34.7 \\
\hline$\beta$-Myrcene & 975 & 1.5 & 1.3 & 1.0 & 1.1 & 1.1 & 1.1 & 1.0 & 1.1 & 1.1 & 1.0 \\
\hline$\beta$-Phellandrene & 1005 & 1.2 & 1.3 & 1.4 & 1.3 & 1.6 & 1.1 & 1.2 & 1.6 & 1.2 & 1.9 \\
\hline Limonene & 1009 & 1.1 & 1.2 & 1.3 & 1.3 & 1.3 & 1.2 & 1.5 & 1.3 & 1.2 & 1.3 \\
\hline Butyl isovalerate & 1022 & $\mathrm{t}$ & $\mathrm{t}$ & $\mathrm{t}$ & $\mathrm{t}$ & $\mathrm{t}$ & $\mathrm{t}$ & $\mathrm{t}$ & $\mathrm{t}$ & $\mathrm{t}$ & $\mathrm{t}$ \\
\hline trans- $\beta$-Ocimene & 1027 & $\mathrm{t}$ & $\mathrm{t}$ & $\mathrm{t}$ & $\mathrm{t}$ & $\mathrm{t}$ & $\mathrm{t}$ & $\mathrm{t}$ & $\mathrm{t}$ & $\mathrm{t}$ & $\mathrm{t}$ \\
\hline$\gamma$-Terpinene & 1035 & 0.1 & 0.1 & 0.1 & $\mathrm{t}$ & $\mathrm{t}$ & 0.1 & $\mathrm{t}$ & $\mathrm{t}$ & $\mathrm{t}$ & $\mathrm{t}$ \\
\hline Terpinolene & 1064 & 0.4 & 0.3 & 0.5 & 0.3 & 0.1 & 0.3 & 0.5 & 0.6 & 0.4 & $\mathrm{t}$ \\
\hline Linalool & 1074 & 0.2 & 0.2 & 0.1 & 0.1 & 0.1 & $\mathrm{t}$ & $\mathrm{t}$ & 0.4 & 0.1 & $\mathrm{t}$ \\
\hline Isopentyl isovalerate & 1084 & 0.1 & 0.1 & $\mathrm{t}$ & $\mathrm{t}$ & $\mathrm{t}$ & $\mathrm{t}$ & $\mathrm{t}$ & $\mathrm{t}$ & $\mathrm{t}$ & $\mathrm{t}$ \\
\hline trans-Pinocamphone & 1121 & $\mathrm{t}$ & $\mathrm{t}$ & $\mathrm{t}$ & $\mathrm{t}$ & $\mathrm{t}$ & $\mathrm{t}$ & $\mathrm{t}$ & $\mathrm{t}$ & $\mathrm{t}$ & $\mathrm{t}$ \\
\hline$\delta$-Terpineol & 1134 & $\mathrm{t}$ & $\mathrm{t}$ & $\mathrm{t}$ & $\mathrm{t}$ & $\mathrm{t}$ & $\mathrm{t}$ & $\mathrm{t}$ & $\mathrm{t}$ & $\mathrm{t}$ & $\mathrm{t}$ \\
\hline Borneol & 1134 & $\mathrm{t}$ & $\mathrm{t}$ & $\mathrm{t}$ & $\mathrm{t}$ & $\mathrm{t}$ & $\mathrm{t}$ & $\mathrm{t}$ & $\mathrm{t}$ & $\mathrm{t}$ & $\mathrm{t}$ \\
\hline$\alpha$-Terpineol & 1159 & 1.5 & 1.1 & 1.7 & 0.7 & 1.5 & 1.3 & 1.8 & 2.6 & 0.9 & 2.2 \\
\hline Methyl thymol & 1210 & $\mathrm{t}$ & $\mathrm{t}$ & 0.1 & $\mathrm{t}$ & $\mathrm{t}$ & $\mathrm{t}$ & $\mathrm{t}$ & 0.1 & 0.1 & $\mathrm{t}$ \\
\hline Phenyl ethyl acetate & 1228 & 0.1 & 0.1 & $\mathrm{t}$ & $\mathrm{t}$ & $\mathrm{t}$ & 0.1 & $\mathrm{t}$ & $\mathrm{t}$ & $\mathrm{t}$ & $\mathrm{t}$ \\
\hline Bornyl acetate & 1265 & 0.3 & 0.3 & 0.2 & 0.3 & 0.2 & 0.2 & $\mathrm{t}$ & 0.2 & 0.1 & $\mathrm{t}$ \\
\hline Carvacrol & 1286 & $\mathrm{t}$ & 0.1 & 0.1 & 0.1 & 0.2 & $\mathrm{t}$ & 0.4 & 0.5 & 0.6 & 0.3 \\
\hline trans-Pinocarvyl acetate & 1278 & 0.1 & 0.1 & $\mathrm{t}$ & $\mathrm{t}$ & $\mathrm{t}$ & 0.1 & $\mathrm{t}$ & $\mathrm{t}$ & 0.4 & $\mathrm{t}$ \\
\hline$\alpha$-Longipinene & 1338 & $\mathrm{t}$ & $\mathrm{t}$ & $\mathrm{t}$ & $\mathrm{t}$ & $\mathrm{t}$ & $\mathrm{t}$ & $\mathrm{t}$ & $\mathrm{t}$ & $\mathrm{t}$ & $\mathrm{t}$ \\
\hline$\alpha$-Cubebene & 1345 & 0.1 & 0.1 & $\mathrm{t}$ & $\mathrm{t}$ & $\mathrm{t}$ & $\mathrm{t}$ & $\mathrm{t}$ & 0.1 & 0.1 & $\mathrm{t}$ \\
\hline$\alpha$-Copaene & 1375 & 0.1 & 0.1 & 0.1 & $\mathrm{t}$ & $\mathrm{t}$ & 0.1 & 0.1 & $\mathrm{t}$ & 0.1 & $\mathrm{t}$ \\
\hline Longifolene & 1399 & $\mathrm{t}$ & $\mathrm{t}$ & $\mathrm{t}$ & 0.1 & $\mathrm{t}$ & $\mathrm{t}$ & 0.1 & 0.1 & $\mathrm{t}$ & $\mathrm{t}$ \\
\hline$\beta$-Caryophyllene & 1414 & 2.9 & 2.4 & 2.0 & 1.9 & 2.3 & 3.2 & 2.4 & 3.1 & 1.4 & 2.6 \\
\hline$\alpha$-Humulene & 1447 & 0.2 & 0.1 & $\mathrm{t}$ & $\mathrm{t}$ & $\mathrm{t}$ & 0.9 & 0.2 & 0.5 & 0.4 & $\mathrm{t}$ \\
\hline trans- $\beta$-Farnesene & 1455 & 0.1 & 0.1 & $\mathrm{t}$ & $\mathrm{t}$ & $\mathrm{t}$ & 0.3 & $\mathrm{t}$ & $\mathrm{t}$ & $\mathrm{t}$ & $\mathrm{t}$ \\
\hline Phenyl ethyl 2-methyl butanoate & 1467 & 0.3 & 0.3 & 0.1 & 0.3 & 0.2 & 0.5 & 0.6 & 1.0 & 0.3 & $\mathrm{t}$ \\
\hline Phenyl ethyl isovalerate & 1468 & 1.1 & 0.9 & 0.6 & 0.7 & 0.6 & 1.1 & 1.6 & 2.0 & 1.0 & 0.4 \\
\hline$\gamma$-Muurolene & 1469 & $\mathrm{t}$ & $\mathrm{t}$ & $\mathrm{t}$ & $\mathrm{t}$ & $\mathrm{t}$ & $\mathrm{t}$ & $\mathrm{t}$ & $\mathrm{t}$ & $\mathrm{t}$ & $\mathrm{t}$ \\
\hline Germacrene-D & 1474 & 4.4 & 4.2 & 6.6 & 4.1 & 6.7 & 4.5 & 3.5 & 8.7 & 3.1 & 9.3 \\
\hline$\alpha$-Muurolene & 1494 & 0.4 & 0.3 & 0.2 & 0.2 & 0.1 & 0.5 & 0.2 & 0.6 & 0.1 & $\mathrm{t}$ \\
\hline$\gamma$-Cadinene & 1500 & 1.2 & 1.0 & 0.7 & 0.7 & 0.4 & 1.5 & 0.7 & 1.1 & 0.7 & $\mathrm{t}$ \\
\hline$\delta$-Cadinene & 1505 & 0.9 & 0.9 & 1.9 & 0.8 & 1.4 & 1.0 & 1.7 & 1.8 & 0.5 & 1.9 \\
\hline$\beta$-Caryophyllene oxide & 1561 & 0.3 & 1.1 & 1.8 & 1.9 & 2.5 & 1.0 & 0.4 & 2.5 & 2.8 & 3.0 \\
\hline epi-Cubenol & 1600 & 0.3 & 0.2 & $\mathrm{t}$ & 0.1 & 0.1 & 0.1 & 0.3 & 0.3 & $\mathrm{t}$ & $\mathrm{t}$ \\
\hline epi- $\alpha$-Cadinol & 1616 & 0.2 & 0.2 & $\mathrm{t}$ & 0.2 & 0.1 & 0.2 & 0.4 & 0.6 & 0.3 & $\mathrm{t}$ \\
\hline$\alpha$-Muurolol & 1618 & 0.3 & 0.2 & 0.2 & 0.1 & 0.8 & 0.3 & 0.2 & 0.1 & $\mathrm{t}$ & 1.4 \\
\hline$\alpha$-Cadinol & 1626 & 0.2 & 0.2 & 0.5 & 0.3 & 2.0 & 0.4 & 0.3 & 0.8 & 0.4 & 3.8 \\
\hline Palmitic acid & 1908 & 0.9 & 0.8 & 0.5 & 0.6 & 1.0 & 0.7 & 0.6 & 0.9 & 0.6 & 1.4 \\
\hline UI A Ppi* & 2006 & $\mathrm{t}$ & 0.1 & 0.6 & 0.2 & 0.4 & $\mathrm{t}$ & $\mathrm{t}$ & 0.3 & 0.1 & 0.6 \\
\hline UI B Ppi* & 2309 & 7.2 & 5.6 & 4.2 & 4.0 & 6.8 & 7.8 & 4.1 & 8.2 & 2.6 & 9.5 \\
\hline \% Identification & & 88.0 & 90.4 & 89.7 & 92.9 & 89.4 & 87.7 & 93.9 & 85.9 & 95.6 & 85.9 \\
\hline \multicolumn{12}{|l|}{ Grouped components } \\
\hline Monoterpene hydrocarbons & & 71.7 & 75.6 & 72.3 & 79.4 & 69.5 & 69.6 & 78.7 & 57.9 & 81.6 & 59.6 \\
\hline Oxygen-containing monoterpenes & & 2.1 & 1.7 & 2.2 & 1.3 & 1.9 & 1.6 & 2.2 & 3.9 & 2.1 & 2.5 \\
\hline Sesquiterpene hydrocarbons & & 10.3 & 9.1 & 11.5 & 7.8 & 10.8 & 12.0 & 8.7 & 15.9 & 6.4 & 13.8 \\
\hline Oxygen-containing sesquiterpenes & & 1.3 & 2.0 & 2.5 & 2.6 & 5.4 & 2.0 & 1.6 & 4.3 & 3.5 & 8.2 \\
\hline Others & & 2.6 & 2.1 & 1.2 & 1.7 & 1.7 & 2.5 & 2.8 & 4.0 & 1.9 & 1.8 \\
\hline
\end{tabular}

RI: In-lab calculated retention indices relative to C9-C24 n-alkanes on the DB-1 column, t: trace (<0.05\%), UI: Unidentified compound.

to R. graveolens EO volatiles, and to Ppi shoots constitutive volatiles, also new volatiles were detected in PpiRg shoots. 2-Undecanone, the major component in $R$. graveolens EO (91\%) (Faria et al., 2013), increased throughout Phase 2 (18-38\%) (Fig. 4b), decreasing after transference to Phase 3 (29\%). During this study, the identity of a previously unidentified component from $R$. graveolens EO (Faria et al., 2013), was ascertained as 8-phenyl-2-octanone by NMR (Figs. $4 \mathrm{~d}$ and Fig. 5). There was no major variation in the relative amount of this compound during Phase 2 and 3 (3-5\%). Four new, as yet unidentified, volatiles (0-3\%) were detected in PpiRg shoots, whose relative amount either declined, increased or remained relatively stable throughout time.

de Feo et al. (2002) tested in vitro phytotoxic activity of $R$. graveolens essential oil and some of its constituents on Raphanus sativus germination and radicle growth and found activity only in the EO and some minor constituents but not with the EO major components, 2-undecanone (47\%) or 2-nonanone (19\%). While showing no detectable phytotoxic activity, $R$. graveolens EO used in the present work differed from that used by de Feo et al. (2002) by displaying a higher amount of 2-undecanone and the presence of the ketone 8-phenyl-2-octanone. 

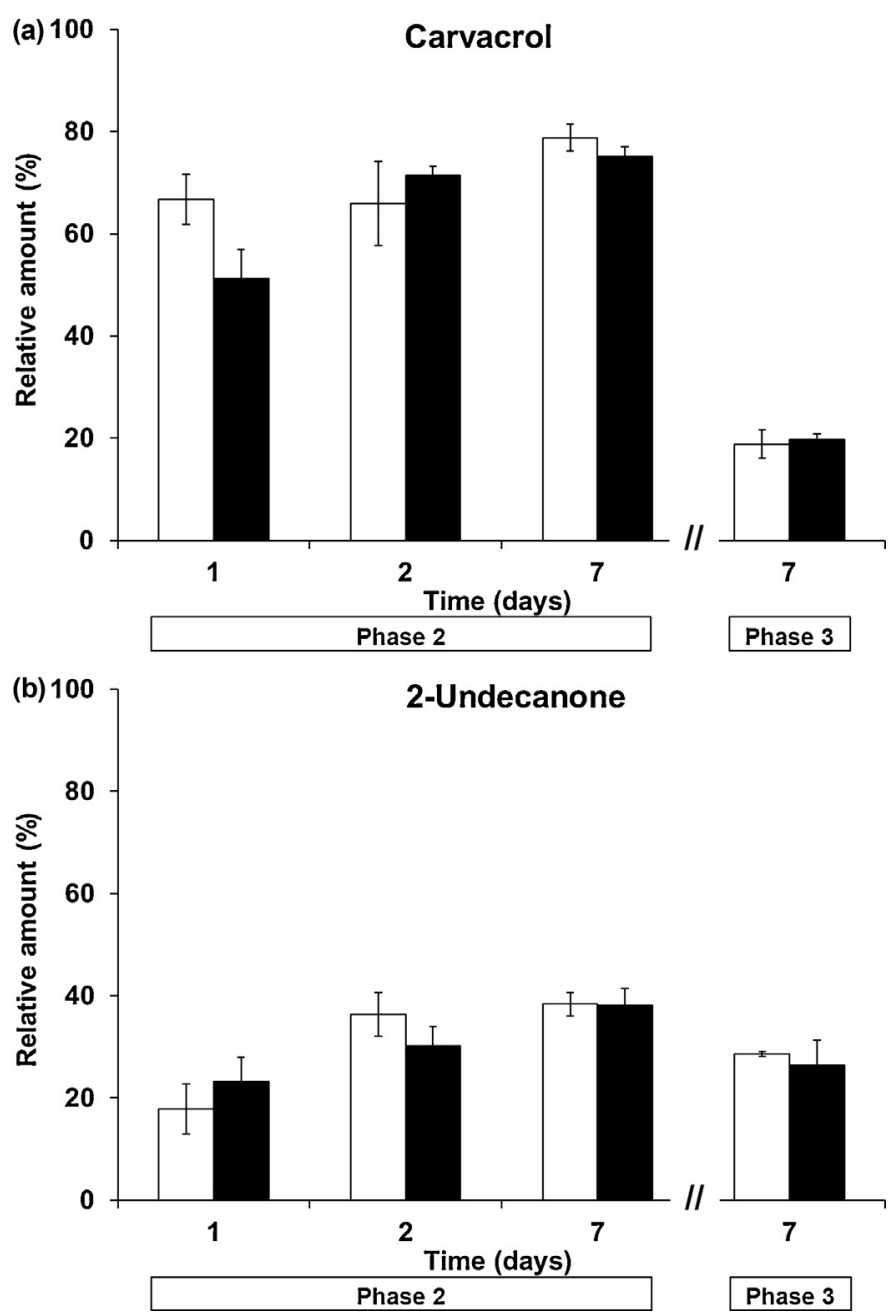

Fig. 4. Variation in the percentage composition of the main components of the EOs added to the culture media. (a) Carvacrol from Satureja montana and (b) 2 undecanone from Ruta graveolens EOs added, at $0.5 \mu \mathrm{l} \mathrm{EO} / \mathrm{ml}$ culture medium, to $P$. pinaster shoots cultures (Ppi) (white columns) and to P. pinaster shoots with PWN co-cultures (PpiBx) (black columns).

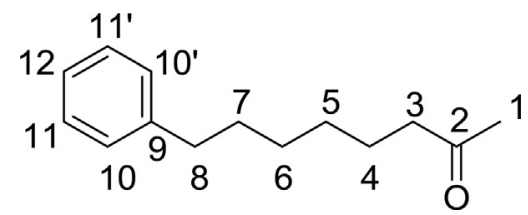

Fig. 5. Chemical structure of 8-phenyl-2-octanone as determined by NMR.

\subsection{Phytotoxicity and nematotoxicity to P. pinaster with B. xylophilus co-cultures}

PpiBx co-cultures and Ppi shoots showed similar morphology (Fig. 2a and d) and volatile profile (Table 1). Likewise, PpiBx cocultures response to EOs addition to culture media was similar at morphological and volatile levels. Again, PpiBx co-cultures shoots transferred to $S$. montana EO-added culture medium developed toxicity symptoms, while $R$. graveolens EO induced no apparent tissue damage.

$S$. montana and $R$. graveolens EOs showed high nematotoxicity in direct contact bioassays (Faria et al., 2013) and were now assessed on B. xylophilus population density in PpiBx co-cultures, during Phase 2 and at the end of Phase 3 (Fig. 1). In PpiBx co-cultures grown in EO-free SH medium (control cultures), PWNs showed a
$62 \%$ increase from day 1 to day 7 of Phase 2 (Fig. 3). Independently of the added EO, PWN population was always lower in EOs-added culture media, comparatively to control cultures (Fig. 3).

In $S$. montana EO-added culture medium PWN population showed no increase while in $R$. graveolens EO-added culture medium increased from $1.2 \pm 0.3$ to $2.8 \pm 0.5 \mathrm{PWNs} / \mathrm{ml}$ culture medium, from day 1 to day 7 in Phase 2. Comparing with PpiBx shoots (control) at day 7 in Phase 2, $7.2 \pm 0.9 \mathrm{PWNs} / \mathrm{ml}$ culture medium, $R$. graveolens EO effectively inhibited $61 \% \mathrm{PWN}$ population increase. After a 7 days recovery (Phase 3 ), PWN population from EO-added cultures was detected below 15\% that of control, indicating that treatment with EOs was effective in controlling PWN population (Fig. 3). EO activity was maintained which may be due to nematotoxic EO components being retained in the shoot tissue. Of the compounds retained in shoots, putative nematotoxic 2-undecanone is known for its biocidal activity. It was first registered in the United States in 1966 for use as a dog and cat repellant and is currently used in households and on ornamental plants as an insecticide. Its use was approved for indoor repellents, in 2014, in the European Union, although with high concerns due to its activity as a mammalian toxicant (European Commission, 2012).

Overall, activity against B. xylophilus is generally attributed to the EOs oxygen-containing terpenic fractions (Faria et al., 2013). According to Ntalli and Caboni (2012), these types of compounds (for ex. compounds with alcohol or phenol functional groups) are known to induce cytotoxicity, damage to the cellular and organelle membranes, act as pro-oxidants on proteins and DNA, and produce reactive oxygen species (ROS).

In the present work, two EOs nematotoxic and their phytotoxic activity were evaluated in a host with parasite in vitro co-culture environment. While $S$. montana EO revealed to be both nematotoxic and phytotoxic, the nematotoxic $R$. graveolens EO controlled PWN population showing negligible phytotoxic effects to $P$. pinaster in vitro shoot cultures and to $P$. pinaster shoots with PWN cocultures. Given these characteristics, $R$. graveolens EO should be further evaluated as an effective nematotoxic pesticide against the PWN. Moreover, $P$. pinaster shoots with PWN co-cultures is a feasible system that allows a preview of how the plant host will react to nematotoxic pesticide application and so contributes in better designing in vivo bioassays on PWD affected plants.

\section{Acknowledgments}

The authors would like to thank Dr. João Caio, Departamento de Química e Bioquímica of Faculdade de Ciências de Lisboa, for his NMR technical advice. M. Mota was partially supported by the EC 7th Framework project REPHRAME KBBE.2010.1.4-09 and by Fundação para a Ciência e a Tecnologia (FCT) under PestC/AGR/UI0115/2011 and PEst-OE/AGR/UI0115/2014. Jorge Faria is grateful to FCT for the PhD grant SFRH/BD/43738/2008. This study was partially funded by FCT, under Pest-OE/EQB/LA0023/2011 and research contract PTDC/AGR-CFL/117026/2010.

\section{References}

Albuquerque, C.C., Camara, T.R., Sant'ana, A.E.G., Ulisses, C., Willadino, L., Marcelino Júnior, C., 2012. Effects of the essential oil of Lippia gracilis Schauer on caulinary shoots of heliconia cultivated in vitro. Rev. Bras. Plantas Med. 14, 26-33.

Andrés, M.F., Gonzáles-Coloma, A., Sanz, J., Burillo, J., Sainz, P., 2012. Nematicidal activity of essential oils: a review. Phytochem. Rev. 11, 371-390.

Angelini, L.G., Carpanese, G., Cioni, P.L., Morelli, I., Macchia, M., Flamini, G., 2003. Essential oils from mediterranean Lamiaceae as weed germination inhibitors. J Agric. Food Chem. 51, 6158-6164.

Barbosa, P., Lima, A.S., Vieira, P., Dias, L.S., Tinoco, M.T., Barroso, J.G., Pedro, L.G. Figueiredo, A.C., Mota, M., 2010. Nematicidal activity of essential oils and volatiles derived from Portuguese aromatic flora against the pinewood nematode, Bursaphelenchus xylophilus. J. Nematol. 42, 8-16.

Barbosa, P., Faria, J.M.S., Mendes, M.D., Dias, L.S., Tinoco, M.T., Barroso, J.G., Pedro L.G., Figueiredo, A.C., Mota, M., 2012. Bioassays against Pinewood nematode: 
assessment of a suitable dilution agent and screening for bioactive essential oils. Molecules 17, 12312-12329.

de Feo, V., de Simone, F., Senatore, F., 2002. Potential allelochemicals from the essential oil of Ruta graveolens. Phytochemistry 61, 573-578.

EPPO, 2012. Data sheets on quarantine pests: Bursaphelenchus xylophilus. http:// www.eppo.int/QUARANTINE/nematodes/Bursaphelenchus_xylophilus/ BURSXY_ds.pdf (accessed 15.03.14.).

European Commission, 2012. Commission directive 2012/14/EU. Official Journal of the European Union. 123/36.

Faria, J.M.S., Nunes, I.S., Figueiredo, A.C., Pedro, L.G., Trindade, H., Barroso, J.G., 2009. Biotransformation of menthol and geraniol by hairy root cultures of Anethum graveolens: effect on growth and volatile components. Biotechnol. Lett. 31, 897-903.

Faria, J.M.S., Barbosa, P., Bennett, R.N., Mota, M., Figueiredo, A.C., 2013. Bioactivity against Bursaphelenchus xylophilus: nematotoxics from essential oils, essential oils fractions and decoction waters. Phytochemistry 94, 220-228.

Faria, J.M.S., Sena, I., Maleita, C.M., Vieira da Silva, I., Ascensão, L., Abrantes, I., Bennett, R.N., Mota, M., Figueiredo, A.C., 2014. In vitro co-culture of Solanum tuberosum hairy roots with Meloidogyne chitwoodi: structure, growth and production of volatiles. Plant Cell Tissue Organ Cult. 118, 519-530.

Faria, J.M.S., Sena, I., Vieira da Silva, I., Ribeiro, B., Ascensão, L., Bennett, R.N., Mota, M., Figueiredo, A.C., 2015. In vitro co-cultures of Pinus pinaster with Bursaphelenchus xylophilus: a biotechnological approach to study the pine wilt disease. Planta 241, 1325-1336.
Figueiredo, A.C., Barroso, J.G., Pais, M.S., Scheffer, J.J.C., 1992. Composition of the essential oils from two populations of Achillea millefolium L. ssp. Millefolium. J. Chromatogr. Sci. 30, 392-395.

Figueiredo, A.C., Barroso, J.G., Pedro, L.G., Scheffer, J.J.C., 2008. Factors affecting secondary metabolite production in plants: volatile components and essential oils. Flavour Fragr. J. 23, 213-226.

Giri, A., Dhingraa, V., Giri, C.C., Singh, A., Ward, O.P., Narasu, M.L., 2001. Biotransformations using plant cells, organ cultures and enzyme systems: current trends and future prospects. Biotechnol. Adv. 19, 175-199.

Grosso, C., Coelho, J.A., Urieta, J.S., Palavra, A.M., Barroso, J.G., 2010. Herbicida activity of volatiles from coriander, winter savory, cotton lavender, and thyme isolated by hydrodistillation and supercritical fluid extraction. J. Agric. Food Chem. 58, 11007-11013.

Mota, M., Vieira, P., 2008. Pine Wilt Disease: A Worldwide Threat to Forest Ecosystems. Springer-Verlag, Heidelberg, Germany, pp. 406 pp.

Ntalli, N.G., Caboni, P., 2012. Botanical nematicides: a review. J. Agric. Food Chem. 60, 9929-9940.

Nunes, I.S., Faria, J.M.S., Figueiredo, A.C., Pedro, L.G., Trindade, H., Barroso, J.G., 2009. Menthol and geraniol biotransformation and glycosylation capacity of Levisticum officinale hairy roots. Planta Med. 75, 387-391.

Schenk, U.R., Hildebrandt, A.C., 1972. Medium and techniques for induction and growth of monocotyledonous and dicotyledonous plant cell cultures. Can. J. Bot. 50, 199-204. 